Check for updates

Cite this: RSC Adv., 2017, 7, 18060

\title{
Influence of releasing graphene oxide into a clayey sand: physical and mechanical properties
}

\author{
Guo-Xiang Zhou, abc Jing Zhong, ${ }^{\text {ab }}$ Heng Zhang, ${ }^{c}$ Xinhua Hu, ${ }^{c}$ Jianlin $\mathrm{Wu}^{\mathrm{c}}$ \\ Nikhil Koratkar ${ }^{d}$ and Xianming Shi (D) *ce
}

Graphene oxide (GO) is increasingly used in various applications, and the implications of this nano-sized material entering the natural environment are of great interest. GO is highly soluble in water, and its accumulation in soil could significantly alter the physical and mechanical properties of the soil. In this laboratory study, we mixed GO with a soil (clayey sand, SC) to systematically study the engineering properties and microstructure of the modified soil. The experimental results reveal that the physical and mechanical properties and microstructure of clayey sand can be significantly changed by the addition of a minute quantity of GO. The liquid limit and plasticity index of the soil steadily increased (up to a GO concentration of $0.08 \mathrm{wt} \%$ ), whereas the plastic limit did not change significantly. The addition of GO (up to 0.08 wt\%) into the soil generally decreased the soil's void ratio under a given hydrostatic consolidation pressure, while increasing its undrained shear strength. Such remarkable modifications of soil by minute amounts of GO can be attributed to the extremely high specific surface area of GO and its stable dispersion in water.

Received 6th February 2017 Accepted 12th March 2017

DOI: 10.1039/c7ra01539a

rsc.li/rsc-advances penetration by the sharp edge of graphene. ${ }^{9-11}$ The transport patterns of GO in aqueous media, as well as its stability (in terms of physical agglomeration in aqueous systems and chemical reduction under sunlight radiation) has been investigated. ${ }^{\mathbf{1 2 - 1 4}}$ Soils are one of the most important constituents of ecological system, where underground water is stored, fruits, vegetables and crops grow and a variety of microorganisms use as the principal habitat. ${ }^{15}$ Soil contamination places high risk on human populations, and the USA Environmental Protection Agency (EPA) estimates that over $10 \%$ of the land mass on the planet has been seriously polluted. ${ }^{16}$ Repair of contaminated soil is difficult and costly, due to the complex physicochemical characteristics of soil and its variation from place to place. ${ }^{17}$ The traditional soil contaminants (e.g. petroleum hydrocarbons, polynuclear aromatic hydrocarbons, pesticides and heavy metals) are mainly in the forms of molecules or ions. In contrast, nanomaterials are much larger (1-100 $\mathrm{nm}$ ) and could result in unforeseen soil pollution problems. ${ }^{18-20}$ Therefore the study of nanomaterial/soil interactions is both timely and warranted.

With abundant hydrophilic functional groups on its surface, GO is likely to exhibit strong interaction with some of the constituents in a soil and thus pose great an impact on the physical and chemical behaviors of the soil. It is thus necessary to systematically investigate the effects of GO on the engineering properties of soils, charge distribution in soils, water retention properties of soils, and oxygen availability in soils, all of which are important for the activities of microorganisms. In this work, we report for the first time the impact of GO on the 
physical and mechanical properties and microstructure of a clayey sand. As detailed later, even a trace amount of GO has a significant impact on such properties of the soil, which results from the high specific surface area of GO and stable dispersion in water. We also report that GO intercalated between soil particles enhances the water absorption capability of this soil. The results suggest that a GO coating on soil particle surfaces could significantly alter the physicochemical environment in the soil.

\section{Experimental}

\subsection{Materials}

The soil employed in this study was purchased from NanFan Industrial Co. (Shanghai, China), the physical and chemical properties of which are listed in Table 1. The soil was classified as a Clayey Sand, SC, and its gradation curve is shown in Fig. 1. Since the stability and behaviors of GO in aqueous solution are sensitive to organic impurities that could be present in the soil, we used X-ray fluorescence (XRF) to examine the chemical composition of the soil. As revealed in Table 2, the soil mainly consists of mineral oxides $\left(\mathrm{SiO}_{2}, \mathrm{Al}_{2} \mathrm{O}_{3}, \mathrm{Fe}_{2} \mathrm{O}_{3}, \mathrm{~K}_{2} \mathrm{O}, \mathrm{CaO}\right.$, etc.). The carbon content in the soil, if any, is negligible, and so are possible effects of organic impurities. This was also confirmed by the examination of the soil sample with an Energy-Dispersive $\mathrm{X}$-ray Spectrometer (data not reported here).

The GO was synthesized from natural graphite powder (325 mesh) by the modified Hummer method. ${ }^{21}$ The specific

Table 1 Physical properties of the soil (clayey sand, SC)

\begin{tabular}{ll}
\hline Property & Value \\
\hline Specific gravity & 2.04 \\
Liquid limit & $26.2 \%$ \\
Plastic limit & $16.1 \%$ \\
Plasticity index & 10.1 \\
Average particle size & $\sim 0.2 \mathrm{~mm}$ \\
Granularity & $\leq 3 \mathrm{~mm}$
\end{tabular}

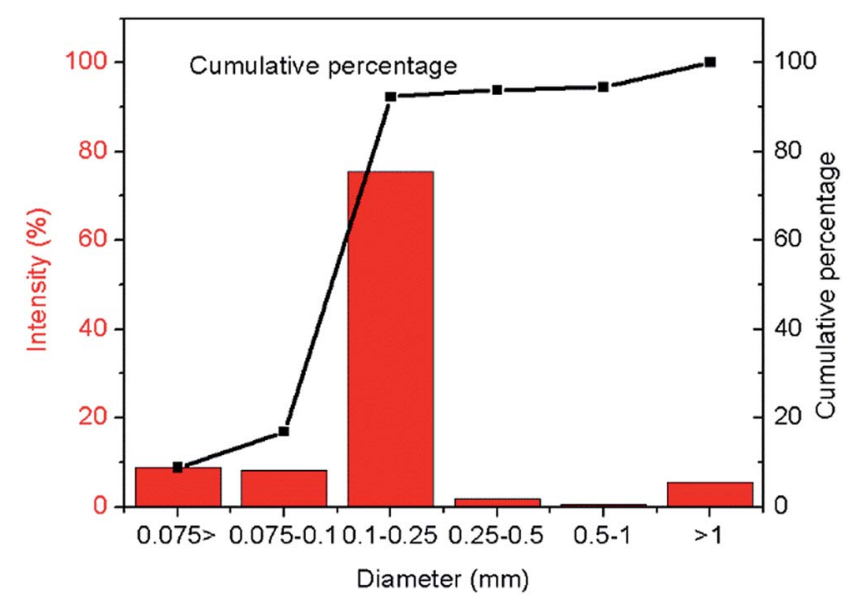

Fig. 1 Gradation curve of the soil used in this study.
Table 2 Chemical composition of the soil, measured by XRF

\begin{tabular}{|c|c|}
\hline Compound & Concentration $(\%)$ \\
\hline $\mathrm{SiO}_{2}$ & 49.083 \\
\hline $\mathrm{Al}_{2} \mathrm{O}_{3}$ & 17.669 \\
\hline $\mathrm{Fe}_{2} \mathrm{O}_{3}$ & 4.098 \\
\hline $\mathrm{K}_{2} \mathrm{O}$ & 2.524 \\
\hline $\mathrm{CaO}$ & 1.228 \\
\hline $\mathrm{MgO}$ & 0.718 \\
\hline $\mathrm{TiO}_{2}$ & 0.521 \\
\hline $\mathrm{P}_{2} \mathrm{O}_{5}$ & 0.105 \\
\hline $\mathrm{MnO}$ & 0.089 \\
\hline $\mathrm{Na}_{2} \mathrm{O}$ & 0.061 \\
\hline $\mathrm{BaO}$ & 0.049 \\
\hline $\mathrm{SO}_{3}$ & 0.044 \\
\hline $\mathrm{ZrO}_{2}$ & 0.025 \\
\hline $\mathrm{CeO}_{2}$ & 0.020 \\
\hline $\mathrm{ZnO}$ & 0.011 \\
\hline $\mathrm{Rb}_{2} \mathrm{O}$ & 0.009 \\
\hline $\mathrm{Cr}_{2} \mathrm{O}_{3}$ & 0.007 \\
\hline $\mathrm{SrO}$ & 0.005 \\
\hline $\mathrm{CuO}$ & 0.004 \\
\hline $\mathrm{NiO}$ & 0.003 \\
\hline $\mathrm{Ga}_{2} \mathrm{O}_{3}$ & 0.002 \\
\hline
\end{tabular}

process is as follows: graphite powder $(\sim 2$ grams $)$ was mixed with concentrated sulfuric acid and sodium nitrate $(\sim 1$ grams) in a $250 \mathrm{ml}$ reaction flask at $0{ }^{\circ} \mathrm{C}$. Then $\sim 6$ grams of potassium permanganate was gradually added with the temperature controlled to not exceed $20^{\circ} \mathrm{C}$, so as to avoid any defect to the plane of GO by overheat. After being stirred for $\sim 10 \mathrm{~min}$, the mixture was heated to $\sim 35{ }^{\circ} \mathrm{C}$ and kept for $\sim 30 \mathrm{~min}$. Next, one liter of deionized water was slowly added in $\sim 20 \mathrm{~min}$, followed by addition of $\sim 30 \mathrm{ml}$ of hydrogen peroxide $(35 \mathrm{wt} \%)$ to reduce residual oxidants. The solid particles were collected via filtration, and washed thoroughly with $5 \mathrm{wt} \% \mathrm{HCl}$ and deionized water. In the final step, the obtained yellowish GO powder was dried in a vacuum oven at $\sim 50{ }^{\circ} \mathrm{C}$.

\subsection{Preparation of GO-soil mixtures}

The water content in the soil was controlled at $\sim 25 \mathrm{wt} \%$. Aqueous solutions with various GO concentrations were prepared via tip-sonication (Fig. 2), before being mixed well with water and the soil to obtain GO modified soil samples with the desired GO weight percentage. To prepare the GO/soil

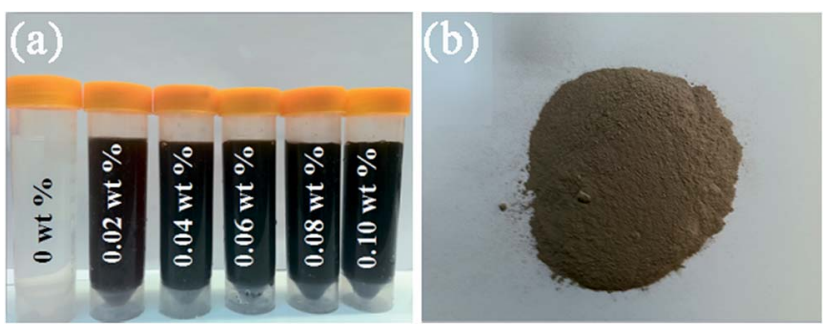

Fig. 2 (a) GO solution with different concentrations; (b) a sample of the soil. 
mixtures, soil particles were dropped into the GO solution gradually under stirring. Since the average size of soil particles was approximately $0.2 \mathrm{~mm}$, which is orders of magnitude higher than that of GO, they were readily dispersed in the GO solution. In addition, the metal salts in each soil particle can help the soil particle attract GO nanosheets onto its surface. Subsequently, the mixtures were sealed in plastic bags and allowed to hydrate for at least $24 \mathrm{~h}$, prior to the preparation of test samples. $T_{0}$ denotes the soil without GO, while $T_{1}, T_{2}, T_{3}, T_{4}$ and $T_{5}$ denote the soil with GO concentrations of $0.02,0.04$, $0.06,0.08$, and $0.1 \%$ by the total dry weight of the soil, respectively.

\subsection{Test procedures}

Both tri-axial tests and oedometer tests ${ }^{22-25}$ were performed in accordance with GBJ123-88 (testing methods of soil and its standards, China).

(1) Plastic and liquid limits tests. These tests of soil were carried out from low water contents to high water contents. Liquid-Plastic Limits Combined Tester (FG-3, Hebei Pengyuan Co., China) with a cone angle of $30^{\circ}$ was used to measure the liquid limit. The water content corresponding to $\sim 10 \mathrm{~mm}$ penetration of the above cone gave the liquid limit of the soil, i.e., the critical moisture content above which the cohesive soil changes from the plastic state to flow state. In this work, a rubbing method was employed to measure the plastic limit, i.e., the critical moisture content above which the cohesive soil changes from the semisolid sate to plastic state. ${ }^{26,27}$ Upon rubbed by hand on the frosted glass, water in the soil gradually evaporates. When the soil sample breaks into a number of segments with the diameter of $\sim 3 \mathrm{~mm}$, the corresponding water content at this time is defined as the plastic limit. The difference between the liquid limit and plastic limit defines the plasticity index, which reveals the thickness of adsorbed water on soil particles. ${ }^{26}$

(2) Oedometer test. The soil was placed into a steel ring (diameter $79.9 \mathrm{~mm}$, height $20 \mathrm{~mm}$ ) and large voids were eliminated mainly by a process of pre-compression using a stress of $10 \mathrm{kPa}$. A series of oedometer tests with $24 \mathrm{~h}$ pre-loading was performed in order to examine the compressibility of the mixtures. The hydrostatic consolidation pressure applied to the specimen was increased from 50 to $400 \mathrm{kPa}$ in five stages. Both compression index $\left(C_{\mathrm{c}}\right)$ and compression coefficient $(\alpha)$ were determined by the void ratio $(e) v s$. soil pressure $(p)$ curve. The compression coefficient $\alpha_{1-2}$ corresponding to the compressive stress from 100 to $200 \mathrm{kPa}$ was used to evaluate the soil's compressibility.

(3) Tri-axial test. The testing equipment was an automatic tri-axial apparatus (Model no. TSZ-1B, Nanjing Soil Instrument). The samples were prepared as follows. First, soil samples with different concentrations of GO were prepared. Then, they were put into a compaction device and layer compacted (5 layers), with each layer having the same weight and a smooth surface. Finally, all soil samples were repacked in a cylinder-shaped sampler of $\sim 80 \mathrm{~mm}$ in height and $\sim 39.1 \mathrm{~mm}$ in diameter. The Unconsolidated-Undrained (UU) tri-axial test was carried out in the strain-controlled mode. After the soil sample was put into the pressure chamber, the confining pressure $\sigma_{3}$ was applied. The shear strain rate was $0.5 \%$ of axial strain per minute. When there was a peak in shearing curve, the shearing continued until axial strain exceed 5\%. However, if there is no peak shearing before the axial strain of $15 \%$, the corresponding stress was assumed to be the fracture stress, which denotes the difference in the maximum of principal stress between vertical stress $\sigma_{1}$ and confining stress $\sigma_{3}$ when the soil is fractured.

(4) Zeta potential and SEM. A New Zetasizer Nano ZSP (Malvern Instruments) was employed to measure the zeta potential. The instrument provides a simple, fast and accurate way to measure zeta potential, and uses a unique disposable capillary cell to ensure that there is no cross-contamination between samples. The samples were prepared as follows. A small amount of soil was milled for $\sim 30$ minutes, then $\sim 0.1$ gram of soil was poured into $\sim 20 \mathrm{ml}$ of deionized water with stirring, followed by sonication for $\sim 30$ minutes. All the samples had very similar $\mathrm{pH}$ values, and thus the effect of $\mathrm{pH}$ difference on the zeta $(\zeta)$ potential was negligible. The $\zeta$ potential of at least five identical samples were determined and their average was taken. The temperature of the room was $20 \pm 2{ }^{\circ} \mathrm{C}$. The embedded model for the calculation of $\zeta$ potential was based on the theory of Helmholtz-Smoluchowski equation. ${ }^{28}$

In addition, the microstructure of the GO modified soil was examined by an FEI HELIOS NanoLab 600i scanning electron microscope (SEM). A typical $20 \mathrm{kV}$ accelerating voltage was used with a scan time of 60 seconds per sampling area.

\section{Results and discussion}

\subsection{Physical properties of GO}

As the most studied graphene derivative, GO has a plethora of functional groups, such as hydroxyl, carboxyl, and epoxy groups, grafted on the surface. These functional groups render GO highly hydrophilic, thus greatly facilitating the processing of graphene-based materials in water. The typical lateral size and thickness of the GO sheets are $\sim 1 \mu \mathrm{m}$, and $1 \mathrm{~nm}$, respectively, as characterized in our previous report. ${ }^{29}$

\subsection{Effect of GO on the plastic and liquid limits and plasticity index of soil}

Fig. 3 shows that the plasticity index and liquid limit of the clayey sand steadily increased with the addition of GO (up to GO concentration of $0.08 \mathrm{wt} \%$ ), whereas the plastic limit of the soil seemed non-sensitive to the addition of GO. The plasticity of soil is mainly controlled by the properties of water that is bound to the soil particles. ${ }^{30,31}$ Unlike free water, the bound water layer has greater viscosity, elasticity and shear strength. ${ }^{32}$ GO nanosheets have a considerable amount of functional groups on the surface, which endows GO with highly hydrophilic properties at near-neutral $\mathrm{pH}$, attracting significant amount of water. ${ }^{33}$ The coating of the soil particles by GO is thus expected to increase 


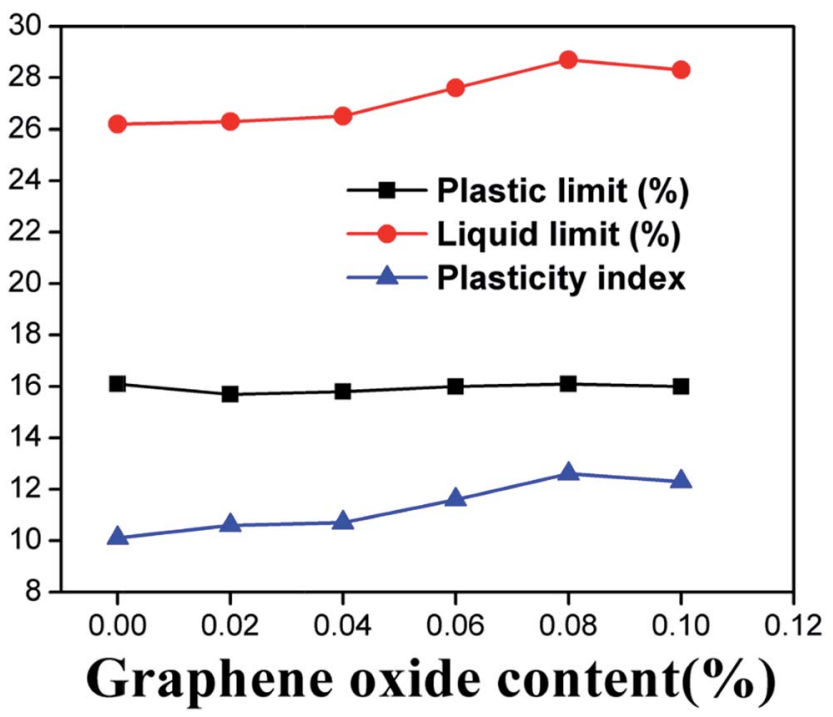

Fig. 3 Property indices of the clayey sand as a function of GO content.

the amount of the bound water, leading to an increase in the liquid limit of the soil. We hypothesize that this mechanism was responsible for the observed influence of GO on the plastic index and liquid limit of the clayey sand. Apparently this mechanism was not significant when the moisture content in the soil was relatively low (below $26 \%$ ) or when the GO content was relatively low (below $0.04 \%$ ).

The plastic limit can be understood as the minimum moisture content for the soil to remain in the plastic state. Under the investigated conditions, the addition of GO in the clayey sand exhibited negligible effect on the soil's plastic limit, as shown in Fig. 3. The mechanisms underlying this observation warrant indepth investigations.

The thickness of the bound water layer is largely determined by the interfacial charge of the soil, which can be

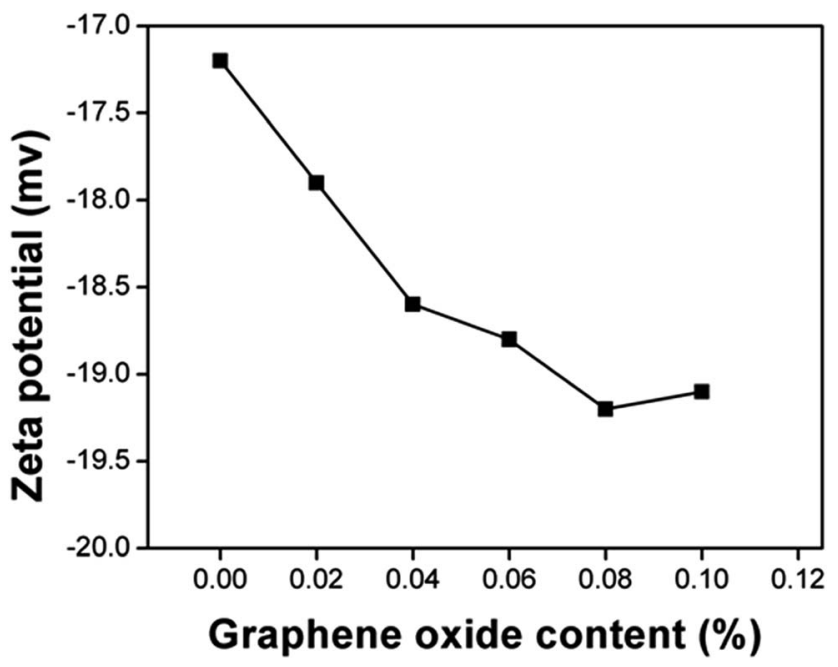

Fig. 4 Zeta potential of the soil as a function of GO content (by weight). The zeta potential of $\mathrm{GO}$ in aqueous solution with $\mathrm{pH}$ value of 7 is $\sim 30$ characterized by the zeta potential. ${ }^{34-36}$ As shown in Fig. 4, the zeta potential of the soil was increased from -17.2 to $-19.2 \mathrm{mV}$ with $\sim 0.08 \mathrm{wt} \%$ of GO addition. The increased zeta potential indicated the enhancement of the capability for soil particles to "capture" the water molecules. ${ }^{37}$ High effectiveness in GO's modification of the soil properties is attributable to the high specific surface area $\left(\sim 2600 \mathrm{~m}^{2} \mathrm{~g}^{-1}\right)$ of GO nanosheets and their stable dispersion in aqueous media. ${ }^{1}$ Consider 0.08 grams of GO mixed with 100 grams of dry soil particles with a density of $2.04 \mathrm{~g} \mathrm{~cm}^{-3}$ (corresponding to the sample $T_{4}$ in this study). Assuming a spherical shape with an average diameter of $0.2 \mathrm{~mm}$, the specific surface area of soil particles is estimated to be approximately $0.0147 \mathrm{~m}^{2} \mathrm{~g}^{-1}$. The surface area of GO $\left(2600 \mathrm{~m}^{2} \mathrm{~g}^{-1} \times 0.08 \mathrm{~g}=208 \mathrm{~m}^{2}\right)$ is much large than that of soil particles $\left(0.0147 \mathrm{~m}^{2} \mathrm{~g}^{-1} \times 100 \mathrm{~g}=1.47\right.$ $\mathrm{m}^{2}$ ). This estimation illustrates that although the concentration or weight fraction of GO sheets is very low, their surface area is sufficient to encapsulate each soil particle with an average number of GO layers of more than 100. It should also be noted that if the soil particles are wrapped tightly by GO nanosheets, the minerals inside of the soil particles would be difficult leach out. ${ }^{38}$ This might be detrimental to the community of microorganisms, since the interaction of soil minerals and microorganisms is critical to their survival. Further, once the soil particles are coated with GO nanosheets, any contaminants present in the soil may not be easily extracted out from the soil, thus hindering the recovery of polluted soil. All these potential effects of GO on the biological environment in soil are important and merit further investigations.

\subsection{Effect of GO on the compressibility of soil}

The relationship between the void ratio $(e)$ and the logarithmic consolidation pressure $(p)$ is presented in Fig. 5 . It can be seen that the void ratio of the soil consistently decreased with the consolidation pressure. Adding GO into the soil generally decreased the void ratio of the soil under a given consolidation

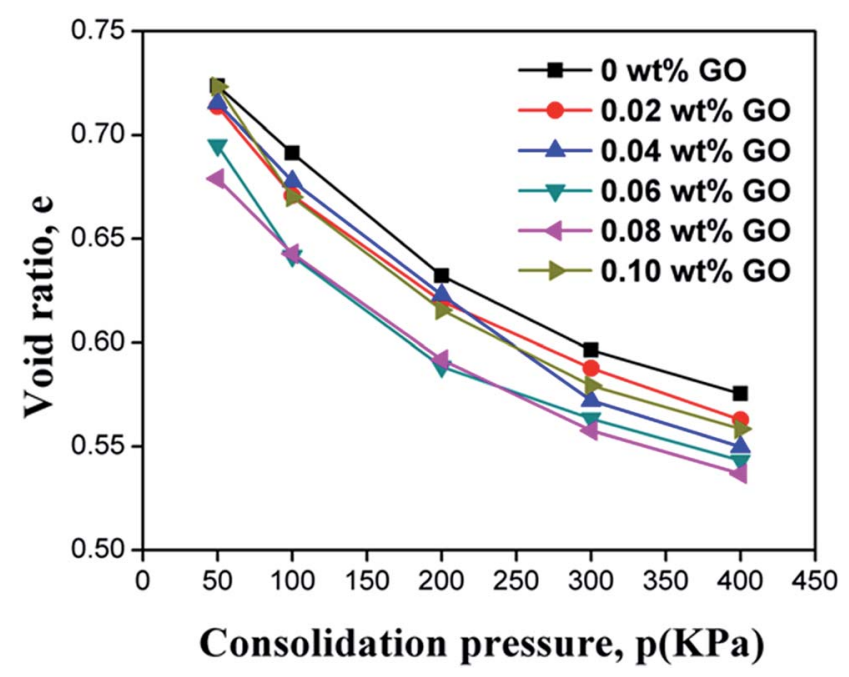

Fig. 5 Compression curves (e-p relationships) of the soil samples. 


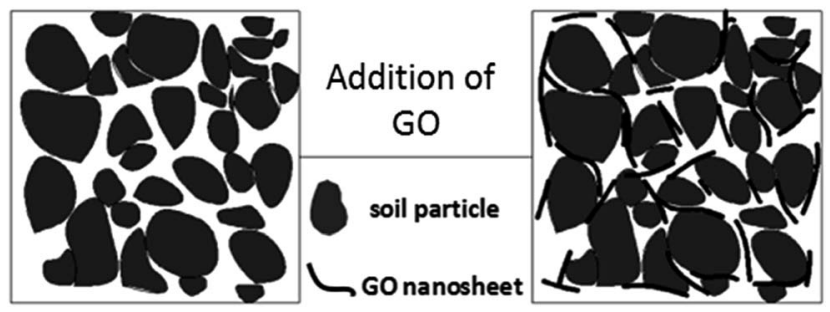

Fig. 6 Schematic illustration of GO nanosheets integrated with soil particles.

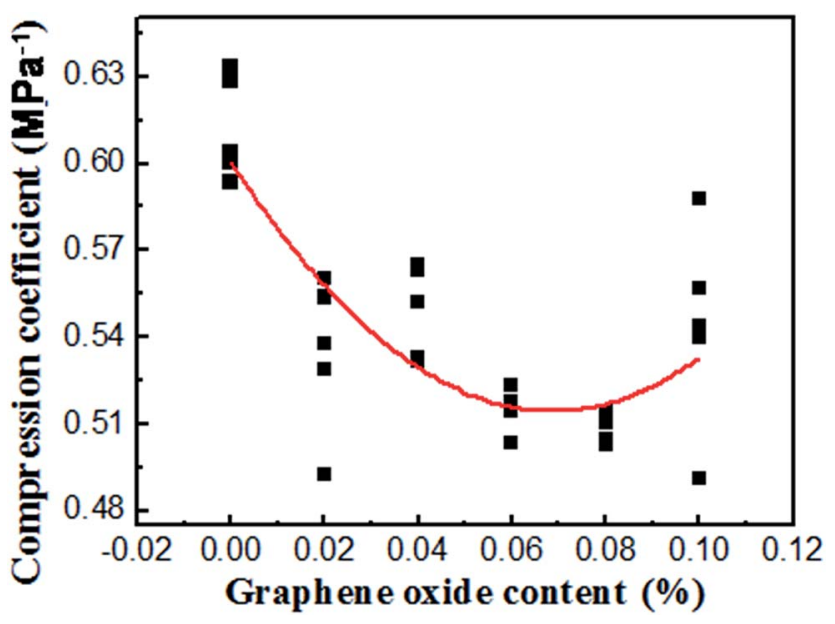

Fig. 7 The relationship between the compression coefficient $\left(\alpha_{1-2}\right)$ and GO content.

pressure, until the GO content exceeded $0.08 \mathrm{wt} \%$. The decreased void ratio after the addition of GO provides compelling evidence that the "free" space between the soil particles, which can be easily compressed by an external force, is reduced..$^{39}$ The GO sheets can physically fill the pores in the soil, as illustrated in Fig. 6. As evidenced by the results in Fig. 5, this filler effect was not the dominant one, due to the low concentration of GO in the soil. Instead, we hypothesize that the presence of GO nanosheets in the soil modifies the structure of the bound water layers, resulting in larger bound water phase which decreases the free space. This is consistent with the observed changes of plasticity and liquid index of the soil by GO. The water confined in the gaps between the soil particles and GO nanosheets is difficult to expel out of the soil samples, thus reducing the void ratio obtained from the compression tests. Once the GO content exceeded $0.08 \mathrm{wt} \%$, however, this "bound water layer" effect became less significant. This is related to the dependency of GO's dispersion with its concentration. In other words, a high GO content in soil (e.g., $0.10 \mathrm{wt} \%)$ leads to the agglomeration of GO nanosheets, thus decreasing the effectiveness of soil modification by GO. This explanation is indirectly validated by the compression coefficient results shown in Fig. 7. Despite the noise in the experimental results, the average trend in Fig. 7 implies a minima in the compression coefficient (i.e., lowest compressibility) at around $0.08 \%$ GO content in the $\mathrm{GO} /$ soil composite.

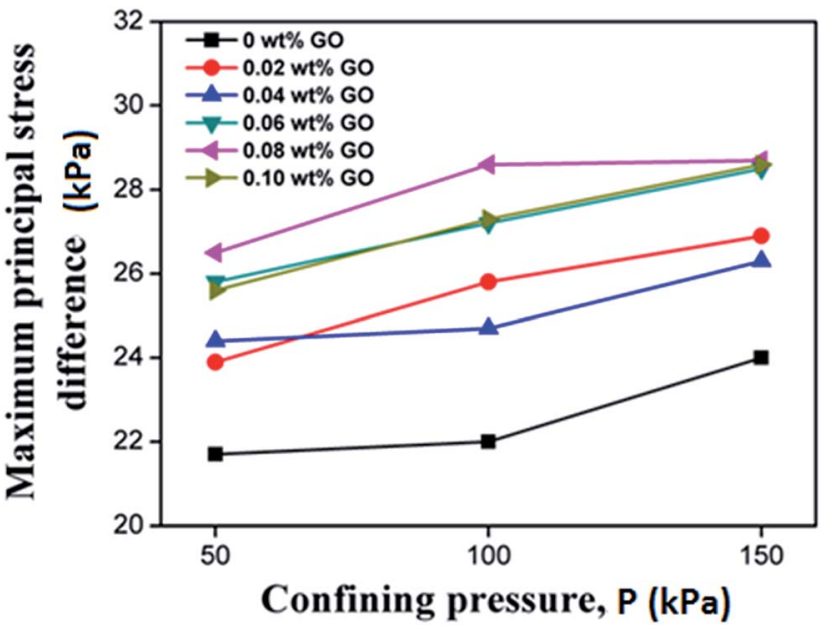

Fig. 8 The relationship between the confining pressure and the maximum principal stress difference.

\subsection{Effect of GO on the shear strength of soil}

To evaluate the effect of GO on the undrained shear strength of the soil, soil samples were tested with the surrounding pressure of 50,100 , and $150 \mathrm{kPa}$, respectively. The maximum principal stress difference is indicative of shear strength according to the theory of solid mechanics, and its dependency on the confining pressure is shown in Fig. 8. The shear strength of all the clayey sand samples increased with the surrounding or confining pressure. Furthermore, Fig. 8 reveals that the shear strength of the soil increased with the GO content until it peaked at the GO content of $0.08 \%$ by weight of the soil. This suggests that the inter-connection between soil particles was enhanced by the presence of well-dispersed GO. This observation is consistent with the results of the $e-p$ relationship in Fig. 5. The shear strength of soil mainly comes from the soil inter-particle interaction, such as the friction force.$^{40}$ Due to the superior mechanical properties of graphene, it has been employed as reinforcement to improve the mechanical properties of various matrixes, such as polymers, metals and ceramics. ${ }^{41}$ Different from these conventional matrices, soil is more like a hydrogel with loose structure, ${ }^{20}$ and the soil skeleton is formed by the interconnected network of soil particles. When GO nanosheets are added, they intercalate between adjacent soil particles, and reinforce the inter-particle connections (Fig. 6). The binding of GO nanosheets to the soil could be further enhanced by the release of metal ions from the soil particles. In addition, the GO can also induce modification of the bound water structure and the double layer on soil particles, thus improving the integrity of the soil network.

According to the Mohr-Coulomb strength theory, the shear strength of soil largely depends on two aspects: the cohesion $C$ and internal friction angle $\varphi$, and both of which can be obtained from the experimental data of soil compression. The relationship is depicted as follows.

$$
\tau_{\mathrm{f}}=C+\sigma \tan \varphi
$$


Table 3 The cohesion $C$ and angle of internal friction $\varphi$ of specimens

\begin{tabular}{lrrrrrr}
\hline Content (\%) & 0 & 0.02 & 0.04 & 0.06 & 0.08 & \multicolumn{1}{c}{0.1} \\
Cohesion, $C(\mathrm{kPa})$ & 10.02 & 11.13 & 11.5 & 12.69 & 12.72 & 11.91 \\
$\varphi\left(^{\circ}\right)$ & 0.65 & 0.84 & 0.54 & 0.4 & 0.63 & 0.85
\end{tabular}

where $\tau_{\mathrm{f}}$ denotes the shear strength and $\sigma$ denotes the vertical pressure.

Table 3 lists the changes of cohesion and internal friction angle of soil with the GO content in the clayey sand. The experimental results reveal that the cohesion increased initially with the GO content until it reached the peak value at the GO content of $0.08 \%$ by weight of the soil. This trend clearly coincides with the increase of undrained shear strength by the presence of well-dispersed GO (as shown in Fig. 8). In contrast, the change of internal friction angle showed no clear trend with the increase in the GO content, implying more than one mechanism at work, which needs to be explored in future studies.

The microstructure of the soil before and after the addition of GO can be seen in Fig. 9. Clearly, the presence of GO very effectively decreases the pores both in terms of number and size, creating a more well-integrated network of soil particles.

\subsection{GO/soil interaction}

As analyzed above, the $\mathrm{GO} /$ soil interaction is the key to understand the behaviors of soil mixed with GO. In light of the very low GO concentration in the soil and high roughness of the pristine soil particles, it is difficult to obtain direct observation of GO coated on the soil particles. As such, the following experiment was designed to shed light on the GO/soil interaction implied in Fig. 9. A two-layer immiscible liquid, with the $0.08 \% \mathrm{GO}$ aqueous solution at its top and dichloromethane at its bottom, was prepared. Since GO nanosheets are super-

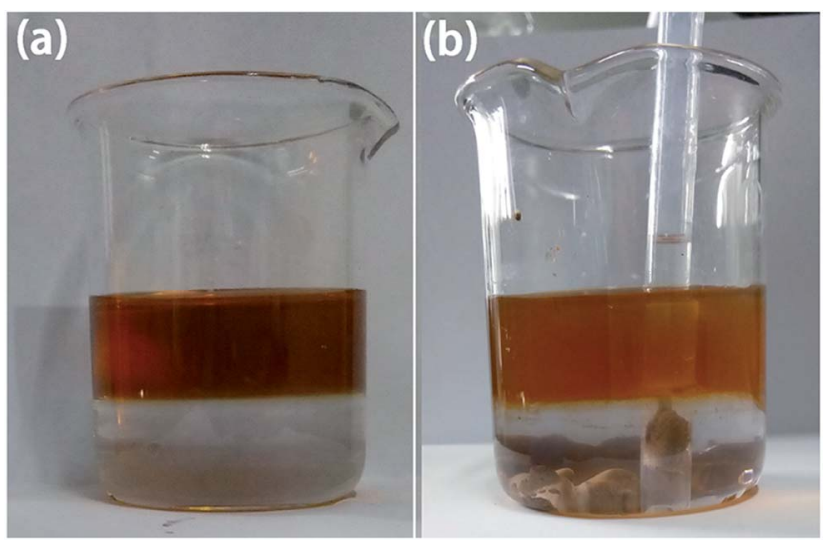

Fig. 10 Images for the two layers of immiscible liquid (GO solution/ dichloromethane), before (a) and after (b) the sedimentation test of soil particles.

hydrophilic, they would rather stay in water. Then, soil particles were gradually dropped into the beaker, and they transported sequentially through the two liquid layers, and eventually settled down on the bottom of the beaker.

Note that GO nanosheets are super-hydrophilic, and it is thermodynamically unfavorable for them to diffuse into dichloromethane. When soil particles transport across the GO solution due to gravitational force, they should absorb a layer of GO film on their surface, if the $\mathrm{GO} /$ soil interaction is strong enough. On the other hand, if the $\mathrm{GO} /$ soil interaction is weak, the physically absorbed GO would be peeled off once in contact with dichloromethane. As implied by Fig. 10, after the soil sedimentation test, the color of GO solution was lighter, indicating the sorption of significantly amount of GO nanosheets onto soil particles which then settled down on the bottom of beaker. Based on the SEM images (Fig. 11), indeed, a thick layer of GO film can be observed that tightly
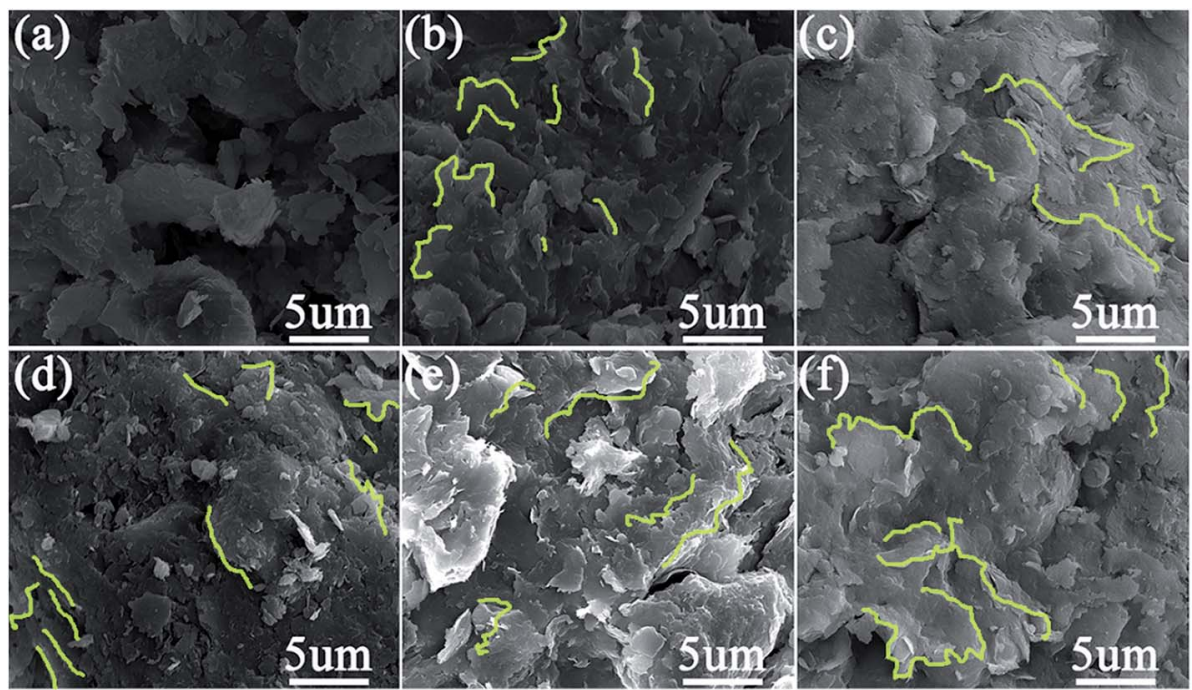

Fig. 9 SEM images of soil samples reinforced by various content of GO: (a) 0 wt\%; (b) 0.02 wt\%; (c) 0.04 wt $\%$; (d) 0.06 wt\%; (e) 0.08 wt\%; (f) 0.10 $w t \%$. 

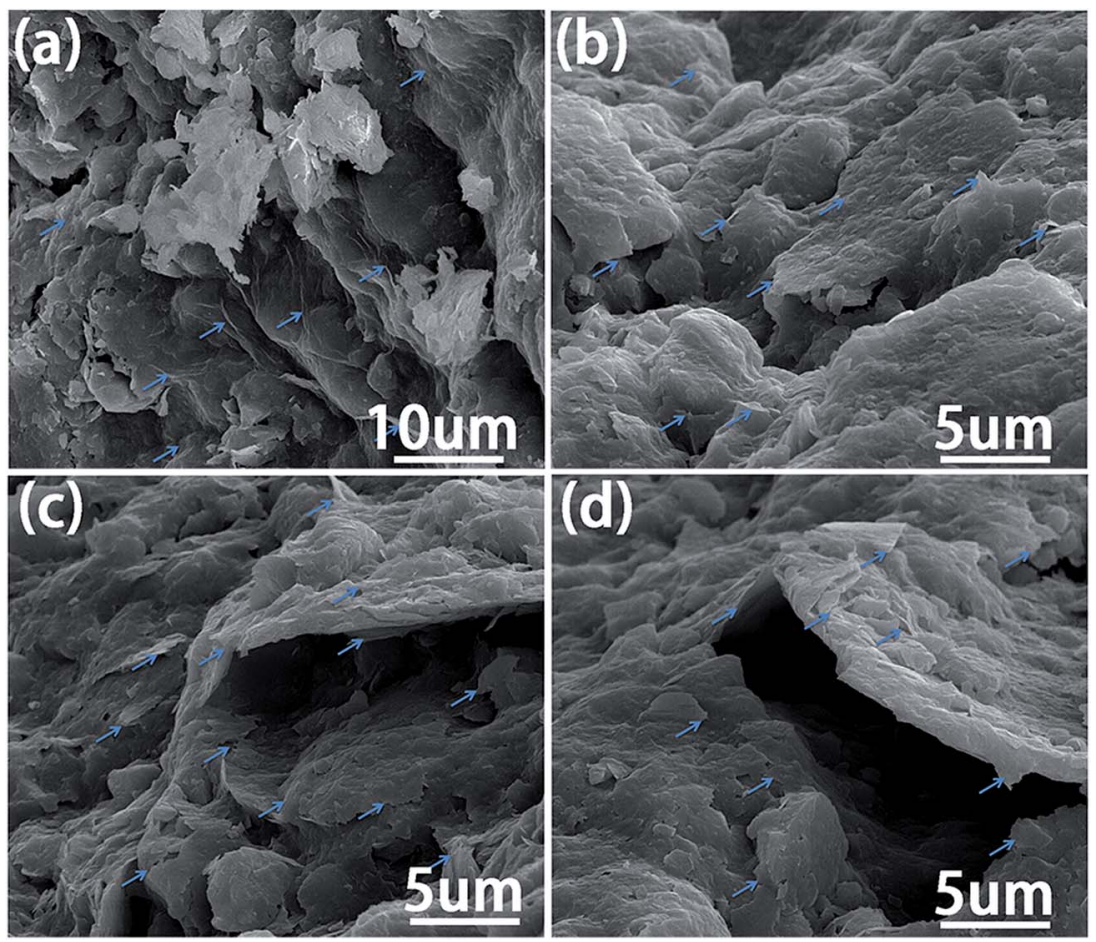

Fig. 11 SEM images of the soil particles after the sedimentation test illustrated in Fig. 10. The arrows indicate their coating by GO.

and uniformly coated on soil particles, suggesting strong $\mathrm{GO} /$ soil interaction.

\section{Conclusions}

We have investigated for the first time the effects of GO on the physical and mechanical properties of a soil (Clayey Sand, SC). With only a small amount of GO (no more than $0.08 \%$ by weight), the properties of the clayey sand can be modified significantly, in terms of liquid limit, plasticity index, compressibility, and undrained shear strength. The effectiveness of GO as a soil modifier stems from its extremely high specific surface area $\left(\sim 2600 \mathrm{~m}^{2} \mathrm{~g}^{-1}\right)$ and very stable dispersion in water. The hydrophilic GO sheets intercalate into the spaces between the soil particles and help to increase the bound water content, leading to less compressibility of the clayey sand. The binding of GO nanosheets to the soil could be further enhanced by the release of metal ions from the soil particles. Such GO coating of soil particles might have detrimental effects for the microorganisms present in soil, and could have long-standing effects on the eco-system of soil, which should be the subject of future investigations.

\section{Acknowledgements}

The authors gratefully acknowledge financial support by the ChuTian Scholar Visiting Professorship Fund provided by the Hubei Department of Education, China, as well as financial support by the National Natural Science Foundation of China (No. 51278390, WPU).

\section{References}

1 Y. Zhu, S. Murali, W. Cai, et al., Graphene and Graphene Oxide: Synthesis, Properties, and Applications, Adv. Mater., 2010, 22, 3906-3924.

2 A. K. Geim and K. S. Novoselov, The rise of grapheme, Nat. Mater., 2007, 6, 183-191.

3 D. Zheng, G. Tang, H. Zhang, et al., In situ thermal reduction of graphene oxide for high electrical conductivity and low percolation threshold in polyamide 6 nanocomposites, Compos. Sci. Technol., 2012, 72, 284-289.

4 A. A. Balandin, S. Ghosh, W. Bao, et al., Superior Thermal Conductivity of Single-Layer Graphene, Nano Lett., 2008, 8, 902-907.

5 W. Cai, Y. Zhu, X. Li, et al., Large area few-layer graphene/ graphite films as transparent thin conducting electrodes, Appl. Phys. Lett., 2009, 95, 123115.

$6 \mathrm{X}$. Li, Y. Zhu, W. Cai, et al., Transfer of large-area graphene films for high-performance transparent conductive electrodes, Nano Lett., 2009, 9, 4359-4363.

7 Y. Hernandez, V. Nicolosi, M. Lotya, et al., High yield production of graphene by liquid phase exfoliation of graphite, Nat. Nanotechnol., 2008, 3, 563-568.

$8 \mathrm{~J}$. N. Coleman, et al., Two-dimensional nanosheets produced by liquid exfoliation of layered materials, Science, 2011, 331, 568-571.

9 W. Hu, C. Peng, W. Luo, et al., Graphene-based antibacterial paper, ACS Nano, 2010, 4, 4317-4323.

$10 \mathrm{~J}$. Chen, X. Wang and H. Han, A new function of graphene oxide emerges: inactivating phytopathogenic bacterium 
Xanthomonas oryzae pv. oryzae, J. Nanopart. Res., 2013, 15, 114.

11 O. Akhavan and E. Ghaderi, Toxicity of graphene and graphene oxide nanowalls against bacteria, ACS Nano, 2010, 4, 5731-5736.

12 J. Zhao, F. Liu, Z. Wang, et al., Heteroaggregation of graphene oxide with minerals in aqueous phase, Environ. Sci. Technol., 2015, 49, 2849-2857.

13 W. C. Hou, I. Chowdhury, D. G. Goodwin Jr, et al., Photochemical transformation of graphene oxide in sunlight, Environ. Sci. Technol., 2015, 49, 3435-3443.

14 Y. Shen and B. Chen, Sulfonated graphene nanosheets as a superb adsorbent for various environmental pollutants in water, Environ. Sci. Technol., 2015, 49, 7364-7372.

15 J. K. Jansson, FORUM: Microbiology the life beneath our feet, Nature, 2013, 494, 40-41.

16 L. Q. Ma, K. M. Komar, C. Tu, et al., A fern that hyperaccumulates arsenic, Shijie Huanjing, 2001, 409, 579.

17 V. M. Fridland, Structure of the soil mantle, Geoderma, 1974, 12, 35-41.

18 M. Wang, S. B. Chen, N. Li, et al., Application of nanoscale amendments in remediation of polluted soils and waters: a review, Chin. J. Eco-Agric., 2010, 18, 434-439.

19 S. Patni and A. L. Bhatia, Nanotechnology: A double edged sword, Asian J. Exp. Sci., 2008, 22, 153-166.

20 M. A. Albrecht, C. W. Evans and C. L. Raston, Green chemistry and the health implications of nanoparticles, Green Chem., 2006, 8, 417-432.

21 W. S. Hummers and R. E. Offeman, Preparation of Graphitic Oxide, J. Am. Chem. Soc., 1958, 80, 1339.

22 L. C. Miao, Z. Z. Yin and S. Y. Liu, Empirical function representing the shear strength of unsaturated soils, Geotech. Test. J., 2001, 24(2), 220-223.

23 O. M. Vilar, A simplified procedure to estimate the shear strength envelope of unsaturated soils, Can. Geotech. J., 2006, 43(10), 1088-1095.

24 M. A. Hossain and J. H. Yin, Shear strength and dilative characteristics of an unsaturated compacted completely decomposed granite soil, Can. Geotech. J., 2010, 47(10), 1112-1126.

25 H. Matsuoka, D. A. Sun, A. Kogane, et al., Stress-strain behavior of unsaturated soil in true triaxial tests, Can. Geotech. J., 2002, 39(3), 608-619.

26 A. O. Landva, E. O. Korpijaakko and P. E. Pheeney, Geotechnical Classification of Peats and Organic Soils, Testing of Peats and Organic Soils, ASTM International, 1983.
27 P. P. Raj, Soil Mechanics \& Foundation Engineering, Pearson Education India, 2008.

28 P. C. Hiemenz and R. Rajagopalan, Principles of Colloid and Surface Chemistry, Marcel Dekker Inc, 3rd edn, revised and expanded, 1997.

29 F. Xiang, R. Mukherjee, J. Zhong, Y. Xia, N. Gu, Z. Yang and N. Koratkar, Scalable and Rapid Far Infrared Reduction of Graphene Oxide for High Performance Lithium Ion Batteries, Energy Storage Mater., 2015, 1, 9-16.

30 K. Tone, M. Kamori and Y. Shibasaki, Adsorbed Cations and Water Film Thickness on the Kaolinitic Clay Surface, J. Ceram. Soc. Jpn., 1993, 101, 1395-1399.

31 M. E. Grismer, Water vapor adsorption kinetics and isothermal infiltration, Soil Sci., 1988, 146, 297-302.

32 M. E. Grismer, Water Vapor Adsorption and Specific Surface, Soil Sci., 1987, 144.

33 P. Poulin, R. Jalili, W. Neri, F. Nallet, T. Divoux, A. Colin, et al., Superflexibility of graphene oxide, Proc. Natl. Acad. Sci. U. S. A., 2016, 113, 11088-11093.

34 C. Y. Ou, S. C. Chien and Y. G. Wang, On the enhancement of electroosmotic soil improvement by the injection of saline solutions, Appl. Clay Sci., 2009, 44, 130-136.

35 G. P. Sheng, H. Q. Yu and X. Y. Li, Extracellular polymeric substances (EPS) of microbial aggregates in biological waste water treatment systems: A review, Biotechnol. Adv., 2010, 28, 882-894.

36 E. Mohamedelhassan and J. Q. Shang, Electrokineticsgenerated pore fluid and ionic transport in an offshore calcareous soil, Can. Geotech. J., 2003, 40, 1185-1199.

37 I. L. Casagrande, Electro-Osmosis in Soils, Geotechnique, 1949, 1, 159-177.

38 H. K. Chae, D. Y. Siberio-Pérez, J. Kim, Y. Go, et al., A route to high surface area, porosity and inclusion of large molecules in crystals, Nature, 2004, 427, 523-527.

39 M. R. Jones, L. Zheng and M. D. Newlands, Comparison of particle packing models for proportioning concrete constituents for minimum voids ratio, Mater. Struct., 2002, 35, 301-309.

40 S. C. Chien, F. C. Teng and C. Y. Ou, Soil improvement of electroosmosis with the chemical treatment using the suitable operation process, Acta Geotech., 2014, 10, 1-8.

41 R. Verdejo, M. M. Bernal, L. J. Romasanta, et al., Graphene filled polymer nanocomposites, J. Mater. Chem., 2010, 21, 3301-3310. 